\title{
Anaplastic pilocytic astrocytoma of the cerebellum presenting with conus medullaris drop metastasis
}

\author{
Jared F. Sweeney ${ }^{1}$, Vaibhav Chumbalkar ${ }^{1}$, Michael D. Staudt ${ }^{1}$, Pouya Entezami*1, Jiang Qian ${ }^{2}$, Vishad V. Sukul ${ }^{1}$ \\ ${ }^{1}$ Department of Neurosurgery, Albany Medical Center, Albany, NY, USA \\ ${ }^{2}$ Department of Pathology, Albany Medical Center, Albany, NY, USA
}

Received: February 21, 2021

DOI: $10.5430 /$ crcp.v8n1p10
Accepted: April 21, 2021

Online Published: May 12, 2021

\begin{abstract}
Due to its rarity, a complete understanding of the clinical behavior, pathogenesis, and diagnostic definition of anaplastic pilocytic astrocytoma (APA) is currently lacking. The optimal clinical management and use of adjuvant therapies has yet to be defined. We present a 64 year-old-female with progressive headaches, dysarthria, and ataxia, who was found to have right cerebellar mass. A gross total resection was achieved through two staged operations. Pathology demonstrated focal areas of necrosis, tumor infiltration, and increased mitotic activity most consistent with APA. Adjuvant chemotherapy and stereotactic radiosurgery were administered. Approximately two years later, the patient presented with symptoms of cauda equina syndrome, and lumbar spine imaging demonstrated a large intradural mass at the conus medullaris with diffuse leptomeningeal enhancement. A biopsy was performed and was consistent with metastatic APA. APA may rarely progress to metastatic disease, most frequently involving the leptomeninges of the posterior fossa and cervical spine. This report represents the first case of metastases distal to the cervicomedullary junction.
\end{abstract}

Key Words: Anaplastic pilocytic astrocytoma, Drop metastases, Glioma

\section{INTRODUCTION}

The literature regarding anaplastic pilocytic astrocytomas (APA) is limited to individual case reports and small case series. Thus, our understanding of their clinical presentation and behavior, pathogenesis, and diagnostic definition is lacking. ${ }^{[1-3]}$ Furthermore, a precise histopathologic definition and grading system for APA has yet to be defined. ${ }^{[3]}$ As such, the optimal clinical management and use of adjuvant therapies is unclear.

We present a rare case of a de novo cerebellar APA, treated with maximal surgical resection and adjuvant chemoradiation, with delayed intradural metastasis at the level of the conus medullaris and diffuse thoracolumbosacral lep- tomeningeal involvement. Metastatic APA is exceedingly rare; it typically disseminates through cerebrospinal fluid (CSF) and tends to be limited to the cranial leptomeninges or cervical spine. ${ }^{[2,4,5]}$ To our knowledge, this is the first documented case of a metastatic APA distal to the cervicomedullary junction.

\section{CASE PRESEntation}

A 64-year-old female with hypertension, obesity, and a 25pack year smoking history presented to the emergency department with several months of progressively worsening headaches, dysarthria, and gait ataxia. Computed tomography (CT) and magnetic resonance imaging (MRI) demon-

\footnotetext{
*Correspondence: Pouya Entezami; Email: ysheinin@mcw.edu; Address: Albany Medical Center, Department of Neurosurgery,43 New Scotland Ave, MC 10A3 Clinic Albany, NY 12208, USA.
} 
strated a poorly defined mass within the right cerebellar hemisphere (see Figure 1A-B). The lesion appeared well circumscribed with surrounding vasogenic edema and central necrosis. CT of the chest, abdomen, and pelvis was negative for a primary malignancy. A suboccipital craniectomy was performed, and intraoperative histopathology was consistent with a low-grade glioma. Post-operative MRI demonstrated residual tumor along the superior aspect of the resection cavity abutting the undersurface of the tentorium (see Figure 2A). Based on the pathological findings (below), a second operation was undertaken to achieve a gross total resection several weeks later. No radiation or chemotherapy was administered in the interim. The patient's headaches and dysarthria subsided and her ataxia improved post-operatively.

Adjuvant chemotherapy and stereotactic radiosurgery of the resection bed were administered after multidisciplinary discussion. A dose of $60 \mathrm{~Gy}$, in 30 treatments over 6 weeks with concurrent Temozolamide therapy for 6 months was initiated. Surveillance MRI demonstrated no tumor recurrence in the interim.
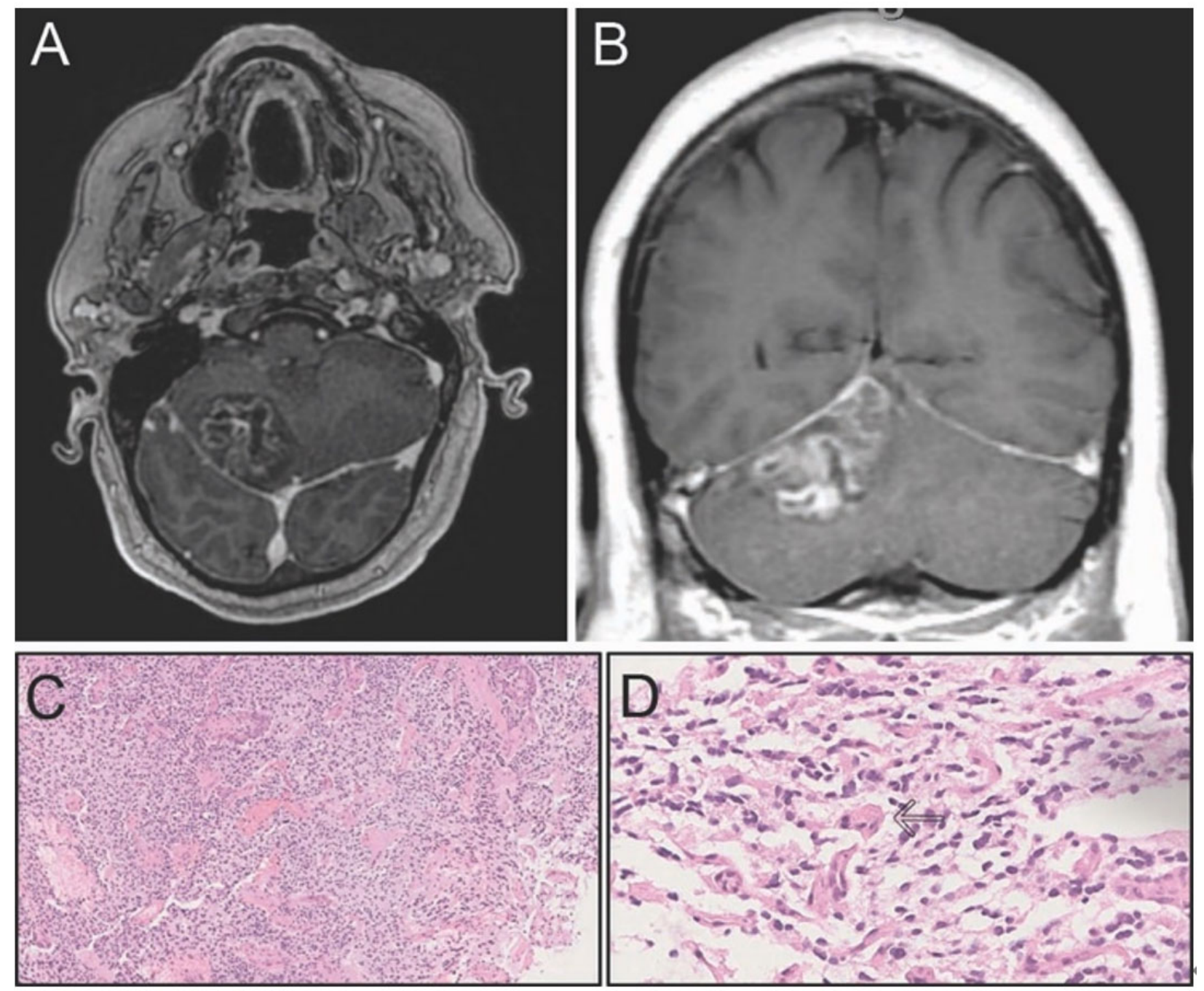

Figure 1. (A) Contrast-enhanced cranial T1-weighted MRI in the axial. (B) coronal planes demonstrating a heterogeneously enhancing, irregular mass in the right cerebellum measuring $3 \mathrm{~cm} \times 3.4 \mathrm{~cm}$, contacting the tentorium but without a dural tail. (C) Histopathological view at 100X magnification consistent with a cellular tumor with increased vascularity and myxoid background. (D) high power view at 400X demonstrates rare Rosenthal fibers.

\subsection{Pathological findings}

Pathological examination demonstrated a myxoidmicrocystic pattern with uniform, oligodendroglial-like cells, separated into vague lobules by fine vasculature, without tumor necrosis or appreciable mitotic activity. There were rare Published by Sciedu Press structures suggestive of Rosenthal fibers and eosinophilic granular bodies (EGB) (see Figure 1C-D). Immunohistochemical staining was noncontributory, and was negative for EGFRvIII and IDH-1. 


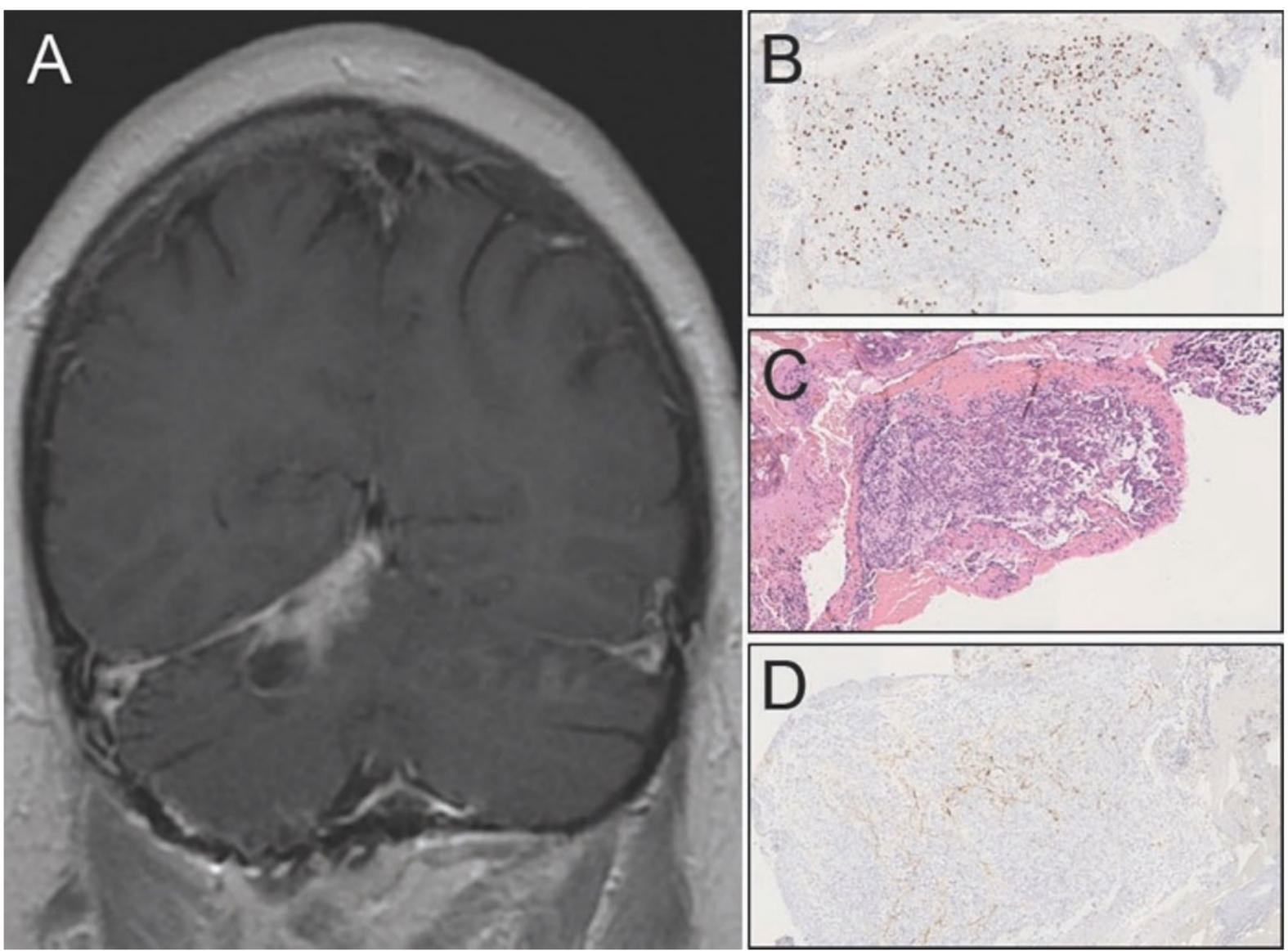

Figure 2. (A) Contrast-enhanced coronal T1-weighted MRI with residual peripherally enhancing tumor cyst and evolution of patchy enhancement along the right superior cerebellum evident 6 weeks following the initial resection. (B) Residual tumor histopathology demonstrates similar morphology to that of that of initial resection (100X). (C) with Ki-67 staining showing increased proliferation $(>40 \%)(100 X)$. (D) Neurofilament staining is consistent with the infiltrative nature of the tumor (100X).

MGMT methylation was not detected. Molecular testing was negative for BRAF V600 mutation. Fluorescence In-Situ Hybridization (FISH) analysis was positive for a deletion of the long arm of chromosome 19 (including 19q13, 83\% of cells) and negative for a deletion of the short arm of chromosome 1 (including 1p36). Three copies of $1 \mathrm{p} 36$ and $1 \mathrm{q} 25$ were observed in $32.5 \%$ of cells, and four copies of $1 \mathrm{p} 36$ and $1 \mathrm{q} 25$ were observed in $9.5 \%$ of cells, suggesting the presence of aneuploid neoplastic cell populations with extra copies of chromosome 1. A well differentiated glioma, likely pilocytic astrocytoma, was felt to be most likely initially. However, the diagnosis was unclear given the unusually low number of Rosenthal fibers and EGBs, greater than expected tumor infiltration, and tumor necrosis.

Histopathological examination from the second resection showed residual tumor with similar cell morphology including rare Rosenthal fibers and EGBs. There were focal areas of necrosis, as well as increased tumor infiltration, mitotic activity, and cell proliferation suggested by Ki-67 staining $(>40 \%$ ) (see Figure 2B-D). These new findings suggested a new diagnosis of a poorly differentiated glioma, most likely representing APA.

\subsection{Subsequent clinical course}

Approximately 2.5 years later, the patient presented with 6 weeks of progressively worsening low back pain, bilateral lower extremity weakness, radiculopathy, and urinary retention. An MRI of the lumbar spine demonstrated a large, poorly-demarcated, avidly enhancing intradural (possibly intramedullary) mass at the conus medullaris, extending from L1 to L4 with leptomeningeal enhancement from T11 to S2 (see Figure 3A). The remainder of the neuraxis MRI was negative for recurrent cerebellar disease. Laminectomy for biopsy, debulking, and expansile duraplasty was performed. Intraoperatively, there was no clear plane between tumor and the conus, and tumor was densely adherent to the nerve roots below the conus. Partial excisional biopsy was performed. 
The patient underwent urgent palliative stereotactic radiosurgery to the lumbosacral spine with a dose of $30 \mathrm{~Gy}$, in 10 treatments over 2 weeks. Temozolomide therapy was restarted and bevacizumab was added. After 12 months the patent resides in a nursing facility and has made minimal gains with respect to her lower extremity function. MRI spine imaging has not demonstrated any lesion progression, although there is new cranial leptomeningeal enhancement.
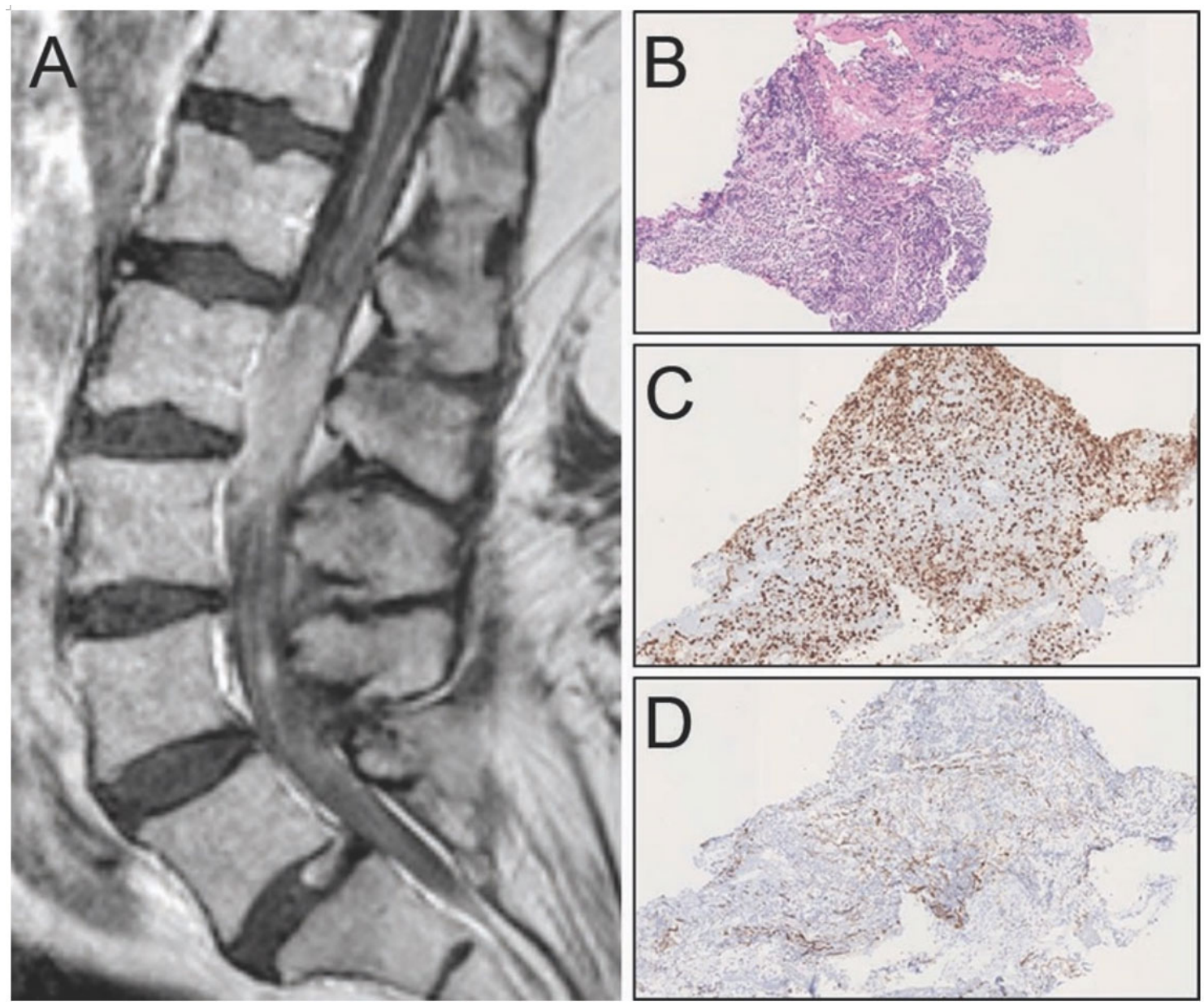

Figure 3. (A) Sagittal contrast-enhanced T1-weighted lumbar MRI demonstrates a large, avidly-enhancing intradural mass that appears to infiltrate the conus medullaris, associated with leptomeningeal enhancement along the cauda equine nerve roots and extending into the thoracic cord. (B) Pathology demonstrates increased cellularity and morphology similar to previous resection cerebellar specimens $(100 \mathrm{X})$, with a high proliferation index $(>90 \%)$ as $(\mathrm{C})$ evidenced by Ki-67 staining (100X). (D) Infiltrative and intramedullary nature of the tumor is appreciated on neurofilament staining (100X).

\subsection{Subsequent pathological findings}

Final pathology was consistent with metastatic APA (see Figure 3B-D). IDH1 and IDH2 mutation analysis was negative. BRAF V600E study was negative. BRAF fusion study by FISH method revealed abnormalities indicative of gain(s) or extra copies of the BRAF gene region on chromosome 7 or extra copies of chromosome 7, a finding of uncertain clinical significance; no BRAF gene rearrangement was found. While $>50 \%$ of pilocytic astrocytomas, especially cerebellar ones, have BRAF rearrangement, the lack of this rearrangement does not exclude the diagnosis of pilocytic astrocytoma.

Unfortunately, there was limited tissue for pathological Published by Sciedu Press examination that precluded molecular analysis, including KIAA1549-BRAF fusion. Since the molecular studies could not support nor exclude the diagnosis of pilocytic astrocytoma, the diagnosis was based on histopathology. This includes microcystic myxoid changes with oligodendrogliallike cells, a pattern often seen in typical bi-phasic pilocytic astrocytoma as well as the presence of Rosenthal fibers/eosinophilic granular bodies. Neuropil infiltration alone does not exclude pilocytic astrocytoma, as there have been reports of widespread infiltration in otherwise classical WHO grade 1 pilocytic astrocytomas. It also needs to be pointed out that oligodendroglial-like cells in this case did 
not indicate an alternative diagnosis of "oligodendroglioma" as there was no evidence of $1 \mathrm{p} / 19 \mathrm{q}$ co-deletion or the IDH1/2 mutations required for that diagnosis.

\section{Discussion}

We report the rare case of a clinically aggressive, likely de novo cerebellar APA, treated with staged gross total resection and adjuvant chemoradiation, metastasizing to the thoracolumbosacral leptomeninges with invasion of the conus medullaris. A thorough review of the literature was conducted to evaluate the current understanding of APA, reported cases of APA metastasis, and difficulties achieving correct histopathologic diagnosis.

APA are most commonly described in adult patients ${ }^{[1,2]}$ with a reported median age of 41.5 and no gender predisposition. ${ }^{[3]}$ Prior radiotherapy ${ }^{[1,2]}$ prior surgical resection, ${ }^{[6]}$ prior low-grade glioma, ${ }^{[6-8]}$ and a history of Neurofibromatosis Type I (NF1) ${ }^{[1,7,9]}$ may be risk factors. Cases of spontaneous, de-novo APA have been rarely reported. ${ }^{[10,11]}$ APA are most commonly infratentorial tumors arising in the posterior fossa, contrasting the common adult predilection for supratentorial tumors. ${ }^{[1]}$ A precise clinical definition is lacking as histologic and molecular pathological studies have demonstrated nonspecific results. ${ }^{[1-3,12-17]}$

Multiple pathophysiologic mechanisms have been proposed based on reports in the literature. ${ }^{[2]}$ In contrast to pilocytic astrocytomas (World Health Organization (WHO) grade I) most common in pediatric patients, ${ }^{[18]}$ APA appear to follow a more aggressive clinical course. ${ }^{[1-3,10,15,19]}$ Though longterm follow-up data is sparse, recurrence, ${ }^{[1,2]}$ progression to glioblastoma ${ }^{[8]}$ or other high-grade tumors, ${ }^{[20]}$ and metasta$\operatorname{sis}^{[2,4,5]}$ have been reported in the literature. In comparison to glioblastoma (WHO grade IV) and anaplastic astrocytoma (WHO grade III), tumor progression appears to take a more indolent course. ${ }^{[1]}$

Due to nonspecific clinical and radiographic features, establishing a pre-operative diagnosis of APA is challenging. ${ }^{[1-3]}$ These tumors share imaging characteristics with demyelinating lesions, inflammatory lesions, low grade gliomas, and high grade gliomas. Additional imaging features that complicate diagnosis include inconsistent patterns of contrast enhancement on MRI, inconsistent demarcation with normal neural tissue, and tumor necrosis. ${ }^{[1]}$ Once diagnosed, treatment involves safe gross total resection when feasible, followed by adjuvant chemotherapy with Temozolomide and/or stereotactic radiosurgery. ${ }^{[1,2]}$

\subsection{Anaplastic pilocytic astrocytoma metastasis}

Metastatic APA is exceedingly rare (see Table 1). Yong et al. reported a case of an insular APA that was subtotally resected and treated with adjuvant chemoradiation that re-presented with epidural metastasis to the $\mathrm{C} 1$ vertebral level 7 years later. Notably, this patient had pre-existing NF1. ${ }^{[2]}$ Grahnke et al. reported a case of a cerebellar vermian APA that was subtotally resected and treated with adjuvant chemoradiation that presented with metastatic recurrence at the cerebellopontine angle involving the leptomeninges of the internal auditory canal approximately 7 years later. ${ }^{[5]}$ Endo et al. reported a case of a left cerebellar hemispheric APA that was subtotally resected and treated with adjuvant stereotactic radiosurgery with metastatic recurrence involving the leptomeninges of the cervicomedullary junction approximately 2 years later. ${ }^{[4]}$ When comparing these 3 reported cases, all involved subtotal resection and adjuvant chemoradiation. Metastatic involvement of the leptomeninges occurred in all 3 cases and never occurred distal to the cervicomedullary junction. ${ }^{[2,4,5]}$

Notably, ours is the first report of a drop metastasis distal to the cervicomedullary junction. This metastatic lesion also became intradural and proceeded to infiltrate the conus medullaris. This aggressive clinical behavior occurred in the absence of a history of NF1.

\subsection{Differential diagnosis}

The differential diagnosis of primary central nervous system tumors causing spinal drop metastases in the adult patient is limited. Most cases of drop metastases are presented in case reports or limited case series. Glioblastoma is the most frequently reported entity with less than $1 \%$ of cases being associated with leptomeningeal dissemination. ${ }^{[21]}$ Spinal drop metastases is more common in the pediatric population, particularly with ependymoma and medulloblastoma. ${ }^{[22]}$ Metastatic tumors to the central nervous system may present with spinal drop metastases as well, sometimes mimicking the radiographic features of high grade primary central nervous system tumors. ${ }^{[23]}$

\subsection{Histopathological and molecular diagnosis of anaplastic pilocytic astrocytoma}

A precise histopathologic definition and grading system for APA is currently lacking as understanding is provided from limited individual case reports and small case series. ${ }^{[1,3,19]}$ Furthermore, there is debate as to whether these tumors represent a separate clinical entity because of the nonspecific histopathological and molecular features. ${ }^{[3]}$ Diagnosis is inconsistent amongst even experienced pathologists and is often based on the presence of features shared by poorly differentiated, high grade tumors and pilocytic astrocytomas. ${ }^{[1,3,19]}$ Identifying a clear diagnostic definition is critical as APA may offer a better prognosis and a more indolent clinical course compared to other high-grade tumors such as anaplastic astrocytoma or glioblastoma. ${ }^{[1,8,18]}$

ISSN 2331-2726 E-ISSN 2331-2734 
Table 1. Reported literature cases of metastatic anaplastic pilocytic astrocytoma

\begin{tabular}{|c|c|c|c|c|c|c|c|c|c|c|}
\hline Reference & Age & Sex & NF1 & $\begin{array}{l}\text { Prior brain } \\
\text { malignancy }\end{array}$ & $\begin{array}{l}\text { Prior } \\
\text { radiation } \\
\text { therapy }\end{array}$ & $\begin{array}{l}\text { Primary } \\
\text { tumor } \\
\text { diameter } \\
(\mathrm{cm})\end{array}$ & $\begin{array}{l}\text { Primary } \\
\text { tumor } \\
\text { location }\end{array}$ & $\begin{array}{l}\text { Primary } \\
\text { tumor } \\
\text { treatment }\end{array}$ & $\begin{array}{l}\text { Time to } \\
\text { metastasis }\end{array}$ & $\begin{array}{l}\text { Metastatic tumor } \\
\text { location }\end{array}$ \\
\hline $\begin{array}{l}\text { Endo et al. } \\
2003^{[6]}\end{array}$ & 70 & F & No & None & None & $\begin{array}{l}\text { Not } \\
\text { available }\end{array}$ & $\begin{array}{l}\text { Left } \\
\text { cerebellar } \\
\text { hemisphere }\end{array}$ & $\begin{array}{l}\text { Subtotal } \\
\text { resection, } \\
\text { gamma knife } \\
\text { radiosurgery }\end{array}$ & $\begin{array}{l}2 \text { years, } 5 \\
\text { months }\end{array}$ & $\begin{array}{l}\text { Leptomeninges at } \\
\text { cervicomedullary } \\
\text { junction }\end{array}$ \\
\hline $\begin{array}{l}\text { Yong et al. } \\
2014^{[22]}\end{array}$ & 33 & M & Yes & None & None & 3.0 & Left insula & $\begin{array}{l}\text { Subtotal } \\
\text { resection, } \\
\text { fractioned } \\
\text { radiotherapy } \\
(60 \mathrm{~Gy}), \\
\text { temozolomide }\end{array}$ & 5 years & Leptomeninges at $\mathrm{C} 1$ \\
\hline $\begin{array}{l}\text { Grahnke } \\
\text { et al. } \\
2018^{[8]}\end{array}$ & 66 & M & No & None & None & 4.1 & $\begin{array}{l}\text { Right } \\
\text { cerebellar } \\
\text { vermis }\end{array}$ & $\begin{array}{l}\text { Subtotal } \\
\text { resection, } \\
\text { fractioned } \\
\text { radiotherapy }\end{array}$ & 7 years & $\begin{array}{l}\text { Leptomeninges of } \\
\text { cerebellopontine } \\
\text { angle and internal } \\
\text { acoustic canal }\end{array}$ \\
\hline $\begin{array}{l}\text { Current } \\
\text { Case }\end{array}$ & 64 & $\mathrm{~F}$ & No & None & None & 3.4 & $\begin{array}{l}\text { Right } \\
\text { cerebellar } \\
\text { hemisphere }\end{array}$ & $\begin{array}{l}\text { ( } 60 \mathrm{~Gy}), \\
\text { temozolomide } \\
\text { Subtotal } \\
\text { followed by } \\
\text { gross total } \\
\text { resection, } \\
\text { fractionated } \\
\text { radiotherapy } \\
\text { ( } 60 \text { Gy), } \\
\text { temozolomide }\end{array}$ & 2.5 years & $\begin{array}{l}\text { Leptomeninges at } \\
\text { thoraco-lumbo-sacral } \\
\text { levels; invasion of } \\
\text { the conus medullaris }\end{array}$ \\
\hline
\end{tabular}

Note. APA - anaplastic pilocytic astrocytoma; NF1 - neurofibromatosis type 1.

APA is most often diagnosed when high pathologic grade and pilocytic features are present. The most common diagnostic characteristics may be brisk mitotic activity (defined as greater than five to ten mitotic figures per high powered field), hypercellularity, foci of necrosis, microvascular proliferation, and malignant cell infiltration of the tumor margin. Pilocytic features may differentiate APA from other high pathologic grade tumors, which include Rosenthal fibers and EGBs. ${ }^{[1,2,8,14-16,19,24]}$ An elevated Ki-67 proliferation index is often present. ${ }^{[2]}$

Molecular genetic abnormalities are frequently present with little clinical utility due to their lacking specificity. ${ }^{[1,15,16]}$ Reported abnormalities include deletions of cyclin dependent kinases involved in cell cycle regulation, abnormalities of the mitogen-activated protein kinase (MAPK) pathway, ${ }^{[3,15]}$ including activating mutations of BRAF and loss of $\mathrm{p} 16^{[15,17]}$ and PTEN, ${ }^{[15]}$ abnormalities of the adenosine triphosphate dependent helicase (ATRX) pathway, ${ }^{[3,14,16]}$ abnormalities of the PI3K/AKT pathway, ${ }^{[15]}$ alternative lengthening of telomeres, mutations in histone proteins $\mathrm{H} 3 \mathrm{~K} 27 \mathrm{M},{ }^{[16]}$ and duplications of growth factor receptors. ${ }^{[12]}$ Isocitrate dehy- drogenase (IDH) wild type is typically present. ${ }^{[3,24]}$ Molecular testing was limited in the current case, but was negative for mutations of BRAF and IDH.

Anaplastic pilocytic astrocytomas is a rare, poorly understood clinical entity with imprecise diagnostic and clinical criteria. Further reporting and research is necessary to delineate its histopathologic and molecular features to determine if APA represents a distinct clinical entity. Development of diagnostic criteria and a pathologic grading system that correlates with clinical behavior may improve prognostic predictions and assist with clinical decision making in this patient population.

\section{ACKNOWLEDGEMENTS}

Funding for the article processing charge was provided by Albany Medical Center Department of Neurosurgery. No other sources of funding were utilized in the making of this report.

\section{CONFLICTS OF INTEREST DisClOSURE}

No conflicts of interest exist for any of the authors included in this report. 


\section{REFERENCES}

[1] Fiechter M, Hewer E, Knecht U, et al. Adult anaplastic pilocytic astrocytoma - a diagnostic challenge? A case series and literature review. Clin Neurol Neurosurg. 2016; 147: 98-104. PMid:27341279. https://doi.org/10.1016/j.clineuro.2016.06.005

[2] Yong EXZ, McKelvie P, Murphy M, et al. Anaplastic pilocytic astrocytoma. J Clin Neurosci. 2014; 21(11): 1993-6. PMid:24954244. PMid: 24954244

[3] Reinhardt A, Stichel D, Schrimpf D, et al. Anaplastic astrocytoma with piloid features, a novel molecular class of IDH wildtype glioma with recurrent MAPK pathway, CDKN2A/B and ATRX alterations. Acta Neuropathol. 2018; 136(2): 273-91. PMid:29564591. https://doi.org/10.1007/s00401-018-1837-8

[4] Endo H, Kumabe T, Jokura H, et al. Leptomeningeal dissemination of cerebellar malignant astrocytomas. J Neurooncol. 2003; 63(2): 191. PMid:12825824. https ://doi.org/10.1023/A:10239835 18341

[5] Grahnke K, Heiferman D, Borys E, et al. Delayed leptomeningeal metastasis of an adult anaplastic pilocytic astrocytoma. Brain Tumor Pathol. 2018; 35(2): 123-6. PMid:29330645. https://doi.org/ 10.1007/s10014-017-0306-8

[6] Ellis JA, Waziri A, Balmaceda C, et al. Rapid recurrence and malignant transformation of pilocytic astrocytoma in adult patients. $\mathrm{J}$ Neurooncol. 2009; 95(3): 377. PMid:19533024. https://doi.or g/10.1007/s11060-009-9935-z

[7] Peters KB, Cummings TJ, Gururangan S. Transformation of juvenile pilocytic astrocytoma to anaplastic pilocytic astrocytoma in patients with neurofibromatosis type I. J Pediatr Hematol Oncol. 2011; 33(5): e198. PMid:21572348. https://doi.org/10.1097/MPH. Ob013e318205e230

[8] Sasaki T, Saito R, Kumabe T, et al. Transformation of adult cerebellar pilocytic astrocytoma to glioblastoma. Brain Tumor Pathol. 2014; 31(2): 108. PMid:23884731. https ://doi.org/10.1007/s100 14-013-0154-0

[9] Tsuda K, Ishikawa E, Saito A, et al. Primary cerebellar pilocytic astrocytoma with anaplastic features in a patient with neurofibromatosis type 1 - case report. Neurol Med Chir (Tokyo). 2011; 51(4): 315. PMid:21515958. https ://doi.org/10.2176/nmc.51.315

[10] Azad A, Deb S, Cher L. Primary anaplastic pilocytic astrocytoma. Journal of Clinical Neuroscience : Official Journal of the Neurosurgical Society of Australasia. 2009; 16(12): 1704. PMid:19815416. https://doi.org/10.1016/j.jocn.2009.04.012

[11] Lach B, Al Shail E, Patay Z. Spontaneous anaplasia in pilocytic astrocytoma of cerebellum. Br J Neurosurg. 2003; 17(3): 250. PMid:14565523. https ://doi.org/10.1080/02688690310001 53152

[12] Ballester LY, Penas-Prado M, Leeds NE, et al. tyrosine kinase domain duplication in pilocytic astrocytoma with anaplasia. Cold Spring Harbor molecular case studies. 2018; 4(2). PMid:29610389. https://doi.org/10.1101/mcs.a002378

[13] Hartmann C, Hentschel B, Wick W, et al. Patients with IDH1 wild type anaplastic astrocytomas exhibit worse prognosis than
IDH1-mutated glioblastomas, and IDH1 mutation status accounts for the unfavorable prognostic effect of higher age: implications for classification of gliomas. Acta Neuropathol. 2010; 120(6): 707. PMid:21088844. https ://doi .org/10.1007/s00401-010 $-0781-z$

[14] Olar A, Tran D, Mehta VP, et al. ATRX protein loss and deregulation of PI3K/AKT pathway is frequent in pilocytic astrocytoma with anaplastic features. Clin Neuropathol. 2019; 38(2): 59. PMid:30499772. https ://doi .org/10.5414/NP301105

[15] Rodriguez EF, Scheithauer BW, Giannini C, et al. PI3K/AKT pathway alterations are associated with clinically aggressive and histologically anaplastic subsets of pilocytic astrocytoma. Acta Neuropathol 2011; 121(3): 407. PMid:21113787. https://doi.org/10.1007/ s00401-010-0784-9

[16] Rodriguez FJ, Brosnan-Cashman JA, Allen SJ, et al. Alternative lengthening of telomeres, ATRX loss and H3-K27M mutations in histologically defined pilocytic astrocytoma with anaplasia. Brain pathology (Zurich, Switzerland). 2019; 29(1): 126. PMid:30192422. https ://doi.org/10.1111/bpa.12646

[17] Yeo YH, Byrne NP, Counelis GJ, et al. Adult with cerebellar anaplastic pilocytic astrocytoma associated with BRAF V600E mutation and p16 loss. Clin Neuropathol. 2013; 32(3): 159. PMid:23196000. https://doi.org/10.5414/NP300564

[18] Louis DN, Perry A, Reifenberger G, et al. The 2016 World Health Organization Classification of Tumors of the Central Nervous System: a summary. Acta Neuropathol. 2016; 131(6): 803. PMid:27157931. https ://doi.org/10.1007/s00401-016-1545-1

[19] Rodriguez FJ, Scheithauer BW, Burger PC, et al. Anaplasia in pilocytic astrocytoma predicts aggressive behavior. The American Journal of Surgical Pathology. 2010; 34(2): 147. PMid:20061938. https : //doi.org/10.1097/PAS.0b013e3181c75238

[20] Blankenburg F, van Landeghem FKH, Plotkin M, et al. Occurrence of a spinal anaplastic pilocytic astrocytoma and a supratentorial PNET in an adolescent. J Pediatr Hematol Oncol. 2007; 29(12): 832. PMid:18090931. https://doi.org/10.1097/MPH. Ob013e3181 580 eb3

[21] Wright $\mathrm{CH}$, Wright J, Onyewadume L, et al. Diagnosis, treatment, and survival in spinal dissemination of primary intracranial glioblastoma: systematic literature review. J Neurosurg Spine. 2019: 1-10.

[22] Kralik SF, O'Neill DP, Kamer AP, et al. Radiological diagnosis of drop metastases from paediatric brain tumours using combination of 2D and 3D MRI sequences. Clin Radiol. 2017; 72(10): 902.e13-.e19. PMid:28545686. https ://doi.org/10.1016/j.crad.2017.04 .016

[23] Mirimanoff RO, Choi NC. Intradural spinal metastases in patients with posterior fossa brain metastases from various primary cancers. Oncology. 1987; 44(4): 232-6. PMid:3039433. https : //doi.org/ 10.1159/000226484

[24] Sugita Y, Nakashima S, Ohshima K, et al. Anaplastic astrocytomas with abundant Rosenthal fibers in elderly patients: a diagnostic pitfall of high-grade gliomas. Neuropathology : official journal of the Japanese Society of Neuropathology. 2013; 33(5): 533. 